\title{
A molecular survey of vector-borne pathogens and haemoplasmas in owned cats across Italy
}

Maria Stefania Latrofa ${ }^{1}$, Roberta latta', Federica Toniolo², Tommaso Furlanello³, Silvia Ravagnan², Gioia Capelli², Bettina Schunack ${ }^{4}$, Bruno Chomel $^{5}$, Andrea Zatelli ${ }^{1}$, Jairo Mendoza-Roldan ${ }^{1}$, Filipe Dantas-Torres ${ }^{1,6}$ and Domenico Otranto ${ }^{1,7^{*}}$

\begin{abstract}
Background: Feline vector-borne pathogens (FeVBPs) have been increasingly investigated for their impact on cat health and their zoonotic potential. The aim of the present study was to assess the prevalence of FeVBPs and haemoplasmas in cats across Italy and to identify potential risk factors linked to their occurrence.

Methods: Blood samples from 958 owned cats living in the North $(n=556)$, Centre $(n=173)$ and South $(n=229)$ of Italy were tested for Babesia spp., Hepatozoon spp., Ehrlichia spp., Anaplasma spp. and filarioids by conventional PCR (CPCR) and for haemoplasmas and Bartonella spp. by SYBR green real-time PCR. Cats included in the study represent a sub-sample from a larger number of animals enrolled in a previous study, which were selected based on the geographical origin. Data on cats' positivity for Leishmania infantum, feline leukaemia virus (FeLV) and for feline immunodeficiency virus (FIV), available from the previous study, were included and examined. Potential risk factors for pathogen infection were assessed in relationship to categorical variables including sex, geographical origin, breed, neutering status and age of cats.

Results: Out of the 958 cats, 194 (20.2\%) were positive for at least one of the tested pathogens, 89 (16\%) from the North, 32 (18.5\%) from the Centre and 73 (31.9\%) from the South of Italy. A high prevalence of FeVBPs was detected in male cats $(n=125,27.8 \%)$, living in the southern part of the country $(n=73,31.9 \%)$, younger than 18 months of age $(n=24,22.4 \%)$ and not neutered $(n=39 ; 27.5 \%)$. In particular, 24 cats $(2.5 \%)$ tested PCR-positive for Bartonella spp., of which $1.6 \%$ for B. henselae and $0.9 \%$ for B. clarridgeiae. A total of 111 cats scored PCR-positive for haemoplasmas (11.6\%), specifically "Candidatus Mycoplasma haemominutum" ( $n=95,9.9 \%)$, M. haemofelis $(n=14,1.5 \%)$ and "Candidatus Mycoplasma turicensis" ( $n=2,0.2 \%)$. Moreover, 39, 31 and 8 cats were positive for FeLV (4.1\%), L. infantum (3.2\%) and FIV (0.8\%), respectively. Co-infections were registered for 19 (9.8\%) cats.
\end{abstract}

Conclusions: These results confirm the occurrence of haemoplasmas and FeVBPs throughout Italy. Preventive measures to protect both animal and human health should be carried out also for owned cats, even if no health status of animals has been assessed in this study.

Keywords: Cat, Vector-borne pathogens, Zoonosis, Haemoplasmas, Bartonella spp., Leishmania infantum, Feline leukemia virus, Feline immunodeficiency virus

\footnotetext{
${ }^{*}$ Correspondence: domenico.otranto@uniba.it

${ }^{1}$ Department of Veterinary Medicine, University of Bari, Valenzano, Bari, Italy

Full list of author information is available at the end of the article
}

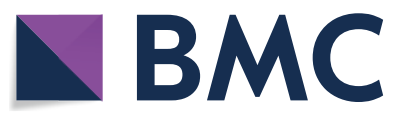

(c) The Author(s) 2020. This article is licensed under a Creative Commons Attribution 4.0 International License, which permits use, sharing, adaptation, distribution and reproduction in any medium or format, as long as you give appropriate credit to the original author(s) and the source, provide a link to the Creative Commons licence, and indicate if changes were made. The images or other third party material in this article are included in the article's Creative Commons licence, unless indicated otherwise in a credit line to the material. If material is not included in the article's Creative Commons licence and your intended use is not permitted by statutory regulation or exceeds the permitted use, you will need to obtain permission directly from the copyright holder. To view a copy of this licence, visit http://creativeco mmons.org/licenses/by/4.0/. The Creative Commons Public Domain Dedication waiver (http://creativecommons.org/publicdomain/ zero/1.0/) applies to the data made available in this article, unless otherwise stated in a credit line to the data. 


\section{Background}

Vector-borne diseases (VBDs), caused by pathogens and transmitted by invertebrate vectors to vertebrate hosts, may represent a relevant health issue for pet animals and humans, considering the close association among them [1]. However, whilst VBDs are widely recognized in dog populations worldwide, cats are considered to be less frequently affected [2-4]. The sub-clinical and non-specific clinical signs and laboratory abnormalities of feline VBDs (FeVBDs) $[2,5]$ may further contribute to the underestimation of their relevance, reflecting in a paucity of data about these diseases $[4,6,7]$. In addition, even if some cat habits, such as grooming, may minimize the success of ectoparasite infestation, their outdoor lifestyle increases the exposure to arthropod vectors, and consequently, to their transmitted pathogens $[2,8-11]$.

Most of the literature generated on FeVBDs worldwide has been focussed on feline leishmaniosis in concomitant with viral infections by feline leukaemia virus (FeLV) and feline immunodeficiency virus (FIV) and on feline bartonellosis or haemoplasmosis [3, 12-17]. In contrast, a relative low number of studies were conducted on Rickettsia spp., Anaplasma spp., Hepatozoon spp. and Babesia spp. [18-21]. FeVBDs have been reported in cat populations in different countries of the Mediterranean basin (e.g. Cyprus, Greece, Spain and Italy) and in Portugal, with large variability in their prevalence due to different diagnostic techniques employed (i.e. serological and/or molecular tests), the animals' lifestyle (i.e. indoor, outdoor) as well as the sample size tested $[5,11,15,18$, 20-27]. These methodological differences make it difficult to draw comparisons for FeVBDs prevalence and to achieve a complete picture for areas such as the Italian Peninsula. Therefore, the aim of this study was to obtain data on the prevalence of feline vector-borne pathogens (FeVBPs) and haemoplasma infections in privately owned cats from different Italian regions using a comprehensive molecular methodology, and to assess the potential role of cats as reservoirs and potential sources of microorganisms that could be transmitted to humans.

\section{Methods}

\section{Animal enrolment}

Feline blood samples $(n=958)$ were received from veterinary analysis laboratories after animal's health check, from different regions of the North $(n=556$, Friuli Venezia Giulia, Liguria, Lombardy, Piedmont, Trentino Alto Adige, Valle D’Aosta, Veneto), Centre $(n=173$, Emilia Romagna, Lazio, Tuscany, Marche, Umbria) and South $(n=229$, Abruzzo, Calabria, Campania, Apulia, Sicily, Sardinia) of Italy (Table 1). Cats included in the study represent a sub-sample from a larger number of animals enrolled in a previous study [17] selected based on the geographical origin. For each region, all blood samples were chosen if cats were less than 15 or only $30 \%$ of them when over 15 animals. Within each region, cats were selected using computer-generated random numbers. All cats were examined according to age (less than 18 months-old, between 18 months and 6 years-old, and more than 6 years-old), sex, neutering status, breed and geographical origin (North: N; Centre: C; South: S) (Table 1). Data on cats' positivity for L. infantum, FeLV and FIV, available from the previous study [17], were included and analysed (Table 1). For all cats included, no information on their health status and on ectoparasitic treatment were available.

\section{Sample collection and molecular procedures}

From each cat, $2 \mathrm{ml}$ of whole blood were collected by cephalic or jugular venipuncture into vacuum tubes EDTA and preserved at $-20^{\circ} \mathrm{C}$ until molecular processing. DNA was extracted from blood using the GenUP Blood DNA Kit (Biotechrabbit, Berlin, Germany), following the manufacturer's recommendations. All DNA samples were tested for Babesia spp., Hepatozoon spp., Ehrlichia/Anaplasma spp., filaroids, haemoplasmas and Bartonella spp. (Table 2). Molecular detection of Babesia spp., Hepatozoon spp., Ehrlichia/Anaplasma spp. and filarioids was performed by conventional PCR (cPCR) using primers targeting partial $18 S$ rRNA gene, $16 S$ rRNA gene and cytochrome $c$ oxidase subunit 1 (cox1) gene, respectively (Table 2) [28-30]. Haemoplasmas and Bartonella spp. detection was performed by the SYBR green real-time PCR using primers and run protocols previously described (Table 2) [31, 32].

Bartonella amplification products were directly sequenced for species identification, whilst haemoplasma-positive samples were amplified by CPCR with primers to allow the sequencing [26] and with primers for the differentiation between Mycoplasma haemofelis and Mycoplasma haemocanis [33] (Table 2). Amplified PCR products were visualized by gel-electrophoresis in $2 \%$ agarose gels containing Gel Red nucleic acid gel stain (VWR International PBI, Milan, Italy) and were documented in Gel Logic 100 gel documentation system (Kodak, New York, USA). All PCR products were purified and sequenced in both directions using the same forward and reverse primers, employing the Big Dye Terminator v.3.1 chemistry in a 3130 Genetic analyzer (Applied Biosystems, California, USA) in an automated sequencer (ABI-PRISM 377). Nucleotide sequences were aligned and analysed using Geneious platform version 9.0 (Biomatters Ltd., Auckland, New Zealand) [34] and compared with available sequences in the GenBank database using Basic Local Alignment 
Search Tool (BLAST; http://blast.ncbi.nlm.nih.gov/ Blast.cgi). For all PCR runs, DNA of pathogen-positive and negative blood samples served as controls.

\section{Statistical analysis}

Possible associations between infections and variables were assessed through univariate analysis while the eventual risk factors for Bartonella spp. and haemoplasmas were assessed through multivariate analysis. Exact binomial test established confidence intervals (CI) with $95 \%$ confidence level. The Chi-square test was used to compare percentages of positivity among categories of the same independent variables as well as the total prevalence of each agent.

For multivariate analysis different logistic regression models were performed using as dependent variable Bartonella spp. or haemoplasma positivity at each time and as independent categorical variables the following: sex, geographical origin (North, Centre and South), breed (European $v s$ others), reproductive status (neutered or not), positivity to other pathogens and as a numerical variable, the increasing age. Colinearity among independent variables was preliminarily assessed using Pearson's correlation coefficient. A $P$-value $<0.05$ was considered as statistically significant. Statistical analysis was performed using StatLib and SPSS for Windows (version 13.0, SPSS, Inc., Chicago, IL, USA).

\section{Results}

Out of the 958 cats, 194 (20.2\%; 95\% CI: $17.8-22.9 \%)$ were positive for at least one FeVBP. Of those, 89 (16\%, 95\% CI: 13.1-19.3\%) came from the North, 32 (18.5\%, 95\% CI: 13.2-25.1\%) from the Centre and 73 (31.9\%, 95\% CI: $26.1-38.2 \%)$ from the South of Italy. A statistically significant difference in pathogen prevalence of infection was detected for male cats $(n=125,28 \%, 95 \%$ CI: $\left.24.0-32.4 \%, X^{2}=31.2, d f=1, P<0.0001\right)$, not neutered cats $\left(n=39,27.5 \%, 95 \%\right.$ CI: $20.7-35.5 \%, \chi^{2}=5.4, d f=1$, $P=0.02)$ and cats living in southern Italy $(n=73,31.9 \%$, 95\% CI: $26-38.2 \%, \mathrm{~N}$ vs S: $\chi^{2}=24.9, d f=1, P<0.0001$; C vs S: $\chi^{2}=9.1, d f=1, P=0.002$ ).

A high prevalence of infection was detected in cats younger than 18 months-old $(n=24,22.4 \%, 95 \% \mathrm{CI}$ : 15.3-31.3\%) (Table 1). In particular, 24 cats (2.5\%; $95 \%$ CI: 1.7-3.7\%) tested positive for Bartonella spp. with Bartonella henselae being the most common species found ( $n=15,1.6 \%$; 95\% CI: 0.9-2.3\%) followed by Bartonella clarridgeiae ( $n=9,0.9 \%, 95 \%$ CI: $0.5-1.8 \%$ ).

Among Bartonella species, a significant difference in prevalence was recorded between age groups $(<18$ months $v s 18$ months $<6$ years: $\chi^{2}=9.5, d f=1, P=0.002$ and $v s \geq 6$ years: $\chi^{2}=14.6, d f=1, P<0.0001$, respectively) and geographical areas of provenance $(\mathrm{N} v s \mathrm{~S}$ : $\chi^{2}=9.5, d f=1, P<0.0001 ; \mathrm{C}$ vs $\left.\mathrm{S}: \chi^{2}=9.5, d f=1, P=0.03\right)$ (Table 1).

For $B$. henselae, a significantly higher prevalence was registered for cats below 18 months compared to those above 18 months of age ( $v s 18$ months $<6$ years of age: $\chi^{2}=5.6, d f=1, P=0.02$ and $v s \geq 6$ years: $\chi^{2}=5.8, d f=1$, $P=0.016$ ), whilst for $B$. clarridgeiae a significant difference in prevalence was recorded between cats below 18 months compared to those above 6 years of age $\left(\chi^{2}=1.0\right.$, $d f=1, P=0.002)$ (Table 1).

A total of 111 cats were positive for haemoplasmas (11.6\%; 95\% CI: 9.7-11.8\%) with a significant difference in prevalence between males and females $\left(\chi^{2}=26.9\right.$, $d f=1, P=0.05$ ) (Table 1) but not between age groups and geographical areas of provenance. For haemoplasmas, the highest prevalence was recorded for "Candidatus Mycoplasma haemominutum" ( $n=95,9.9 \%$; $95 \%$ CI: 8.1-12.0\%), with a statistically significant difference recorded between sexes $\left(\chi^{2}=33.7, d f=1, P<0.0001\right)$, followed by $M$. haemofelis ( $n=14,1.5 \%$, 95\% CI: $0.86-2.4 \%)$ and "Candidatus Mycoplasma turicensis" ( $n=2 ; 0.2 \%$, 95\% CI: 0.04-0.76\%) (Table 1). A prevalence of infection of $4.1 \%(n=39), 3.2 \%(n=31)$ and of $0.2 \%(n=8)$ were registered for FeLV, L. infantum and FIV, respectively (Table 1).

A statistically significant difference in prevalence was recorded for $L$. infantum infection between males and females cats $\left(\chi^{2}=7.7, d f=1, P=0.006\right)$, for the neutering status $\left(\chi^{2}=5.1, d f=1, P=0.02\right)$ and for cats living in southern Italy ( $\mathrm{N} v s \mathrm{~S}: \chi^{2}=21, d f=1, P<0.0001 ; \mathrm{C}$ vs $\mathrm{S}$ : $\left.\chi^{2}=8.2, d f=1, P=0.004\right)$. Similarly, a statistically significant difference was recorded for the neutering status of cats positive for FIV $\left(\chi^{2}=7.9, d f=1, P=0.005\right)$ (Table 1$)$.

Co-infections were found in $19(9.8 \%)$ cats, specifically co-infections with more than two pathogens were recorded in four cats positive for " $\mathrm{Ca}$. Mycoplasma haemominutum" $+L$. infantum + FIV + FeLV $(n=1)$, $M$. haemofelis $+L$. infantum $+\mathrm{FIV}+\mathrm{FeLV}(n=1)$, "Ca. Mycoplasma haemominutum" $+B$. henselae $+L$. infantum $(n=1)$ and with M. haemofelis + L. infantum + FIV $(n=1)$. No DNA of Ehrlichia/Anaplasma spp., Babesia spp., Hepatozoon spp. and filarioids was amplified.

The risk factor analysis revealed that cats from southern Italy were more likely to be positive for Bartonella spp. $(\operatorname{ExpB}=2.500)$ but not for haemoplasmas. Male sex, older age and FIV positivity were risk factors for haemoplasmas and not for Bartonella spp. (Table 3). With the exception of FIV, no other co-infection resulted as risk factor for Bartonella spp. and haemoplasmas, respectively. 


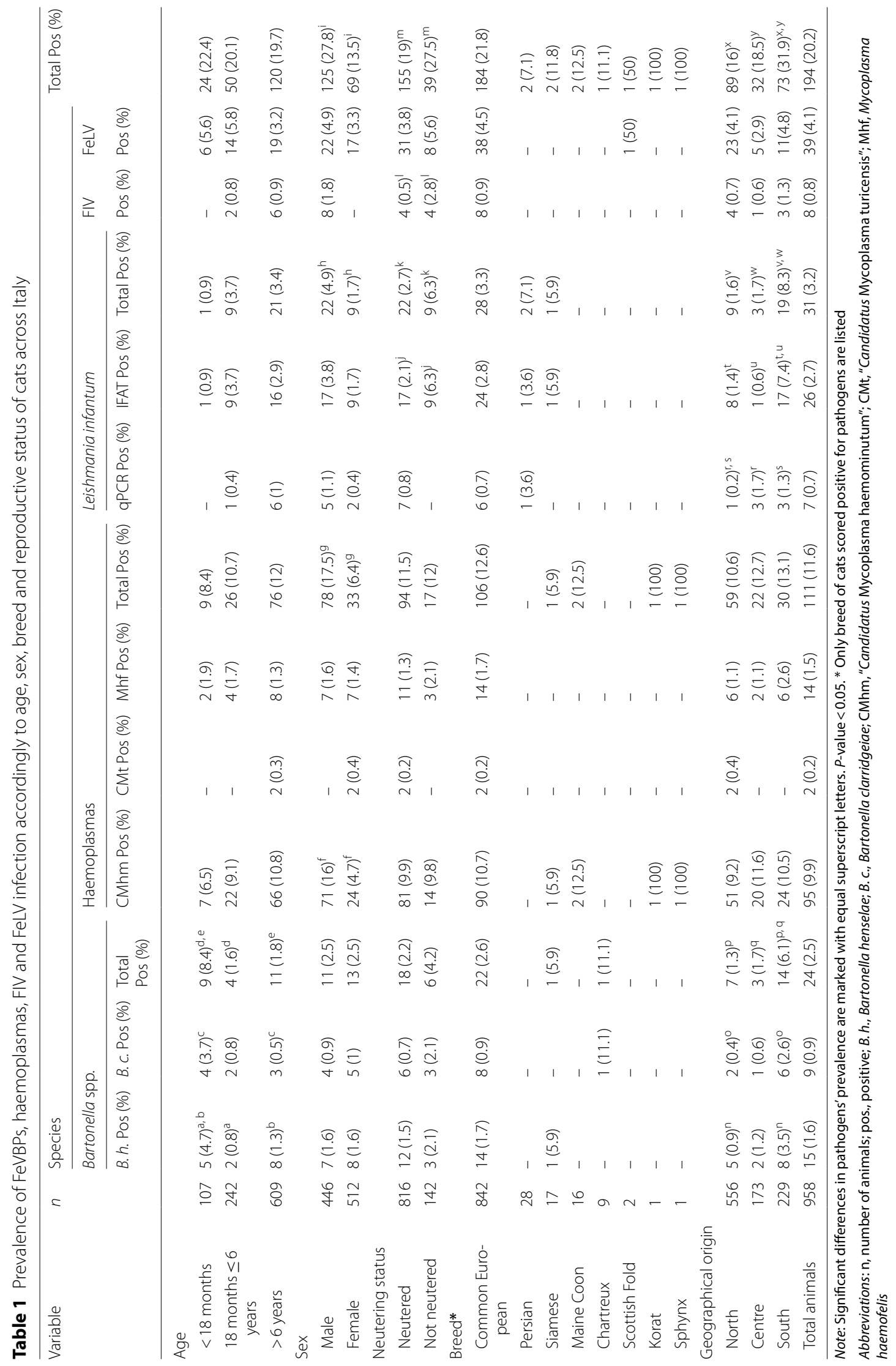


Table 2 Primers and target genes used for pathogen detection in cats across Italy

\begin{tabular}{|c|c|c|c|c|}
\hline Pathogens & Primer sequence $\left(5^{\prime}-3^{\prime}\right)$ & Target gene & $\begin{array}{l}\text { Amplicon size } \\
\text { (bp) }\end{array}$ & References \\
\hline \multirow[t]{2}{*}{ Haemoplasmas } & aMycf: AGCAATRCCATGTGAACGATGAA & $16 \mathrm{~S}$ rRNA & 127 & {$[31]$} \\
\hline & ${ }^{a}$ Mycr1:TGGCACATAGTTTGCTGTCACTT & & & \\
\hline \multirow[t]{2}{*}{ Haemoplasmas } & bMycE929f: ACGGGGACCTGAACAAGTGGTG & 165 rRNA & 259 & [26] \\
\hline & bMycE1182r: AGGCATAAGGGGCATGATGACTTG & & & \\
\hline \multirow[t]{2}{*}{ Mycoplasma haemofelis/M. haemocanis } & bRNasePF1: CTGCGATGGTCGTAATGTTG & RNaseP & 166 & [33] \\
\hline & bRNasePR1: GAGGAGTTTACCGCGTTTCA & & & \\
\hline \multirow[t]{3}{*}{ Bartonella henselae/B. clarridgeiae } & BART-LC-GEN-F: ATGGGTTTTTGGTCATCGAGT & Citrate synthase & 190 & [32] \\
\hline & BART-LC-HEN-R: AAATCGACATTAGGGTAAAGTTTTT & & & \\
\hline & BART-LC-CLA-R: CAAGAAGTGGATCATCTTGG & & & \\
\hline \multirow[t]{2}{*}{ Ehrlichia spp./Anaplasma spp. } & EHR16SD: GGTACCYACAGAAGAAGTCC & 165 rRNA & 345 & [29] \\
\hline & EHR16SR: TAGCACTCATCGTTTACAGC & & & \\
\hline \multirow[t]{2}{*}{ Babesia spp./Hepatozoon spp. } & RLBF: GAGGTAGTGACAAGAAATAACAATA & 185 rRNA & 460 & [28] \\
\hline & RLBR: biotin-TCTTCGATCCCCTAACTTTC & & & \\
\hline \multirow[t]{2}{*}{ Filarioids } & NTF:TGATTGGTGGTTTTGGTAA & $\operatorname{cox} 1$ & 660 & {$[30]$} \\
\hline & NTR: ATAAGTACGAGTATCAATATC & & & \\
\hline
\end{tabular}

a Primers used in real-time PCR for haemoplasma detection and differentiation

b Primers used in conventional PCR for haemoplasma detection and differentiation

Blast analysis of representative sequences showed a nucleotide identity of $99-100 \%$ with those of Bartonella spp. and haemoplasmas available on GenBank (B. clarridgeiae: GU056189; B. henselae: KX499328; "Ca. Mycoplasma haemominutum": EU839980; “Ca. Mycoplasma turicensis": KR905457 and M. haemofelis: EU078617).

\section{Discussion}

The molecular detection of FeVBPs and haemoplasmas carried out in this study allowed to estimate the presence of pathogens within a large population of cats across Italy, with "Ca. Mycoplasma haemominutum" (9.9\%) being the most prevalent pathogen in cats, followed by $L$. infantum (3.2\%), B. henselae (1.6\%), "Ca. Mycoplasma haemofelis" (1.5\%) and B. clarridgeiae (0.9\%). For the other FeVBPs investigated, the overall prevalence of infection for Bartonella spp. (2.5\%) is similar to that detected in a previous molecular investigation in cats with an indoor lifestyle from the South and Centre of Italy (4.8\%) [11].

However, these data are in contrast with the prevalence for Bartonella spp. molecularly (up to 38.1\%) [18] and serologically (up to $48.7 \%$ ) detected in outdoor or freeroaming cats with ectoparasite infestation $[4,11,15,18$, 21]. A similar high seroprevalence was reported in Spain (50\%) [35] and Greece (58.8\%) [23]. The higher prevalence for $B$. henselae (1.6\%) compared to B. clarridgeiae $(0.9 \%)$ is not surprising, as domestic cats are considered to be the main reservoir for $B$. henselae, the causative agent of cat-scratch disease $[13,36]$. The same difference of infection rates between $B$. henselae and $B$. clarridgeiae has been reported in cat populations from southern and insular regions of Italy [18], even if, a higher level of infection rate was registered for both Bartonella species (up to $21.4 \%$ for B. henselae and $16.6 \%$ for B. clarridgeiae), likely due to the outdoor lifestyle and ectoparasite infestation of cats examined [18]. Similarly, B. henselae was more frequently retrieved than $B$. clarridgeiae in cat populations from other European countries (i.e. Cyprus, Portugal, Germany, Greece and Spain) [5, 22-24, 37]. Furthermore, the significantly higher prevalence of bacteraemia for Bartonella spp. in young cats (8.4\%) compared to adults (1.8\%) detected in this study is in line with previous findings $[36,38]$. The significant difference in the prevalence of Bartonella spp. infection found across Italy (i.e. North, Central $v s$ South regions) may be related to the different climate conditions among regions, which could have influenced the cat infection for this parasite $[13,36,38$, 39].

The high prevalence of haemoplasmas (11.6\%) observed in this study is in line with results reported previously in owned cats from southern Italy (18.3\%) [11], even if lower than that found in a stray cat population of northwestern Italy (31.3\%) [40]. The significantly higher prevalence of infection by haemoplasmas in male cats is similar to that reported in previous studies, further indicating that sex and age may be risk factors for haemoplasma infections in cats $[26,41,42]$. The higher infection rate reported in older cats in these studies was not found to be significant in the data presented here, although cats older than 6 years displayed a higher infection rate (12\%) than younger cats $(8.4 \%)$, presumably because of the increasing risk of acquiring chronic subclinical infection 
over their lifetime [27]. Furthermore, no significant differences were found in the regional prevalence of haemoplasma infection in cats of the Italian Peninsula. Overall, the prevalence of haemoplasma infection found in this study was lower than that recorded in stray cats from different regions of Italy, where up to $16.7 \%$ and $1.3 \%$ were recorded for " $\mathrm{Ca}$. Mycoplasma haemominutum", and for M. haemofelis and "Ca. Mycoplasma turicensis" [18, 26, $40,41]$ respectively, suggesting that cats with an outdoor lifestyle are at higher risk of haemoplasma infection. Furthermore, the association between FIV and haemoplasma infection revealed in this study, was concordant with those reported in several studies for cats population from different European countries (Italy, Spain, Portugal, Serbia, Cyprus) [5, 41, 43-45] suggesting that animals infected with these retroviruses were more susceptible to haemoplasma infection than the FIV-negative cats.

The absence of Hepatozoon and Babesia in cats tested might be a consequence of a non-exposure to infected ticks. This result was expected, even if Babesia microti has been previously detected by serology $(20.3 \%)$ and molecularly $(0.8 \%)$ in southern $[11,18]$ and northern Italy [46], respectively. No infection with other Babesia spp. was detected before in cats living in central and southern Italy $[11,19]$. Differently, a high infection level (up to 8.1\%) was observed for other Babesia spp. (i.e. Babesia vogeli and Babesia canis) in cat populations from Portugal [24, 47]. Similarly, the fact that no Hepatozoon DNA was amplified in this study was not surprising as this infection is not common within outdoor feline population of Italy [11]. Hepatozoon spp. are sometimes found in areas with high tick exposure, e.g. a low molecular prevalence $(0.3-4.1 \%)$ detected for Hepatozoon felis in outdoor cats from Sicily [15] and few cases of $H$. felis, $H$. canis and Hepatozoon silvestris infections in cats in southern Italy [48]. In contrast, the overall molecular prevalence of $H$. felis infection was found to be much higher in other countries such as Spain, Portugal, Cyprus (from $1.6 \%$ to $37.9 \%$ ) [5, 22, 24, 47, 49]. The lack of Ehrlichia/Anaplasma spp. in cats tested was concordant with previous studies, where no DNA was amplified from animals living in southern Italy $[11,15,18]$, and with only one cat positive for A. phagocytophilum in the north of the country [46]. Conversely, antibody prevalence of up to $26.9 \%$ for A. phagocytophilum and $16.2 \%$ for $E$. canis was recorded in stray and/or outdoor cats from central and southern Italy [11, 18, 21]. A similar discrepancy in the molecular versus serological detection of Ehrlichia and Anaplasma spp. was described in feline populations from other countries of Europe (i.e. Spain, Portugal, Germany and Greece) [22, 24, 37, 47, 50]. Indeed, whilst DNA detection seems to be infrequent, with only A. phagocytophilum and A. platys DNA occasionally amplified, an antibody prevalence of $A$. phagocytophilum ranging from 2 to $8 \%$ has been reported in cats in Spain [50, 51], 13.5\% in southern Portugal [52], 16.2\% in Germany [53] and 22.1\% in Sweden [54]. Even though no filarial DNA was amplified in the present study, this does not exclude the risk of Dirofilaria spp. infection, as they are known to occur in dogs and cats in different Italian regions [55].

\section{Conclusions}

Although this study presents some limitations due to the lack of information on the health status and ectoparasitic treatments in the enrolled cats, data presented indicate that FeVBPs and haemoplasmas should be more investigated in privately-owned cats. Particular attention should be paid to Bartonella spp. infections, especially by $B$. henselae, which causes cat-scratch disease in humans $[13,56]$. Furthermore, diseases associated with latent haemoplasma infections in both healthy and immunocompromised human patients are of emerging concern. In particular, M. haemofelis was detected in an immunodeficiency virus-infected human from Brazil who was co-infected with $B$. henselae, suggesting that $M$. haemofelis may have zoonotic potential

Table 3 Significant risk factors (ExpB) for Bartonella spp. and haemoplasmas in cats across Italy

\begin{tabular}{|c|c|c|c|c|c|c|c|}
\hline Independent variable & B & SE & Wald & $d f$ & $P$-value & $\operatorname{Exp}(B)$ & $95 \%$ Cl for $\operatorname{Exp}(B)$ \\
\hline \multirow[t]{3}{*}{ Cats from South } & Bartonella spp. risk factors & & & & & & \\
\hline & 0.916 & 0.336 & 7.444 & 1 & 0.006 & 2.500 & $1.294-4.828$ \\
\hline & Haemoplasma risk factors & & & & & & \\
\hline Sex (male vs female) & 0.560 & 0.113 & 24.388 & 1 & 0.000 & 1.751 & $1.402-2.187$ \\
\hline Increasing age & 0.339 & 0.110 & 9.509 & 1 & 0.002 & 1.404 & $1.132-1.742$ \\
\hline FIV positive & 2.177 & 0.913 & 5.681 & 1 & 0.017 & 8.823 & $1.472-52.861$ \\
\hline
\end{tabular}

Note: Variables entered on the models at step 1: provenance (NCS), reproductive status, breed, sex, age, FIV and FeLV positivity. Bartonella and haemoplasmas positivity were entered as independent variable in each model

Abbreviations: B, estimated coefficient; $\mathrm{SE}$, standard error; Wald, Wald statistic; df, degrees of freedom; $\mathrm{P}$, significance value; Exp (B), predicted change in odds for a unit increase in the predictor 
[57]. Consequently, preventive measures against ectoparasites, for non-infected cats as well as infected cats after an appropriate treatment need to be implemented to protect both animals and humans living in the same environment. Increased awareness regarding both FeVBPs and haemoplasmas in cats is advocated.

\section{Abbreviations}

FeVBPs: feline vector-borne pathogens; VBP: vector-borne pathogen; VBDs: vector-borne diseases; FeLV: feline leukemia virus; FIV: feline immunodeficiency virus; CPCR: conventional PCR; cox1: cytochrome coxidase subunit 1; Cl: confidence interval.

\section{Acknowledgements}

The paper has been sponsored by Bayer Animal Health in the framework of the 15 th $\mathrm{CVBD}^{\circledR}$ World Forum Symposium.

\section{Authors' contributions}

MSL, RI and DO conceived the research study, analysed the data and drafted the manuscript. MSL, FT and SR performed laboratory analyses. LMS, TF and GC contributed to data analysis and interpretation and revised the manuscript. LMS, RI, BS, BC, AZ, GC, JM-R, FDT and DO wrote and revised the manuscript. All authors read and approved the final manuscript.

\section{Funding}

This study was funded by Bayer Animal Health (Monheim, Germany) and partially by the Ministry of Health (project code RC IZSVE 04/2016). FDT is the recipient of a research fellowship from Conselho Nacional de Desenvolvimento Científico e Tecnológico (CNPq; 313118/2018-3).

\section{Availability of data and materials}

All data supporting the conclusions of this article are included within the article.

\section{Ethics approval and consent to participate}

Samples of cats were sent from six veterinary diagnostic laboratories distributed throughout Italy to the Parasitology Unit of the Department of Veterinary Medicine, University of Bari (Italy). Samples were originally received for animal's health check analyses. This study was approved by the ethical committee of the Department of Veterinary Medicine of the University of Bari, Italy (Prot. Uniba 7/17). Informed consent was obtained from the owners of enrolled cats.

\section{Consent for publication}

Not applicable.

\section{Competing interests}

The authors declare that they have no competing interests.

\section{Author details}

${ }^{1}$ Department of Veterinary Medicine, University of Bari, Valenzano, Bari, Italy. ${ }^{2}$ Istituto Zooprofilattico Sperimentale delle Venezie, Legnaro, Padova, Italy.

${ }^{3}$ San Marco Veterinary Clinic and Laboratory, Veggiano, Padova, Italy. ${ }^{4}$ Bayer Animal Health $\mathrm{GmbH}$, Leverkusen, Germany. ${ }^{5}$ Department of Population Health and Reproduction, School of Veterinary Medicine, University of California, Davis, USA. ${ }^{6}$ Department of Immunology, Aggeu Magalhães Institute, Fundação Oswaldo Cruz (Fiocruz), Recife, Brazil. ${ }^{7}$ Department of Pathobiology, Faculty of Veterinary Science, Bu-Ali Sina University, Felestin Sq., Hamedan, Iran.

Received: 9 January 2020 Accepted: 24 February 2020

Published online: 21 April 2020

\section{References}

1. Baker PJ, Soulsbury CD, lossa G, Harris S. Domestic cat (Felis catus) and domestic dog (Canis familiaris). In: Gehrt SD, Riley SPD, Cypher BL, editors.
Urban carnivores. Ecology, conflict and conservation. Baltimore: John Hopkins University Press; 2010. p. 157-72.

2. Otranto D, Dantas-Torres F. Canine and feline vector-borne diseases in Italy: current situation and perspectives. Parasit Vectors. 2010;3:2.

3. Pennisi MG, Cardoso L, Baneth G, Bourdeau P, Mirò G, Koutinas G, et al. LeishVet update and recommendations on feline leishmaniosis. Parasit Vectors. 2015;8:302

4. Otranto D, Dantas-Torres F, Mihalca AD, Traub RJ, Lappin M, Baneth G. Zoonotic parasites of sheltered and stray dogs in the era of the global economic and political crisis. Trends Parasitol. 2017;33:813-25.

5. Attipa C, Papasouliotis K, Solano-Gallego L, Baneth G, Nachum-Biala Y, Sarvani $E$, et al. Prevalence study and risk factor analysis of selected bacterial, protozoal and viral, including vector-borne, pathogens in cats from Cyprus. Parasit Vectors. 2017;10:130.

6. Lappin MR. Update on flea and tick associated diseases of cats. Vet Parasitol. 2018:254:26-9.

7. Pennisi MG, Persichetti MF. Feline leishmaniosis: is the cat a small dog? Vet Parasitol. 2018;251:131-7.

8. Maroli M, Pennisi MG, Di Muccio T, Khoury C, Gradoni L, Gramiccia M. Infection of sand flies by a cat naturally infected with Leishmania infantum? Vet Parasitol. 2007;145:357-60.

9. Maia C, Gomes J, Cristóvão J, Nunes M, Martins A, Rebêlo E, et al. Feline Leishmania infection in a canine leishmaniasis endemic region. Portugal. Vet Parasitol. 2010;174:336-40.

10. Pennisi MG, Marsilio F, Hartmann K, Lloret A, Addie D, Belák S, et al. Bartonella species infection in cats: abcd guidelines on chapter iii-vectorborne pathogens in cats from south Italy: prevention and management. J Feline Med Surg. 2013;15:563-9.

11. Persichetti MF, Pennisi MG, Vullo A, Masucci M, Migliazzo A, SolanoGallego L. Clinical evaluation of outdoor cats exposed to ectoparasites and associated risk for vector-borne infections in southern Italy. Parasit Vectors. 2018;11:136.

12. Bartonellosis Guptill-Yoran L. Infectious diseases of dog and cat. 3rd ed. St. Louis: Saunders-Elsevier; 2006. p. 510-8.

13. Chomel BB, Boulouis HJ, Maruyama S, Breitschwerdt EB. Bartonella spp. in pets and effect on human health. Emerg Infect Dis. 2006;12:389-94.

14. Sykes JE. Feline hemotropic mycoplasmas. Vet Clin N Am Small Anim Pract. 2010:40:1157-70.

15. Otranto D, Napoli E, Latrofa MS, Annoscia G, Tarallo VD, Greco G, et al. Feline and canine leishmaniosis and other vector-borne diseases in the Aeolian Islands: pathogen and vector circulation in a confined environment. Vet Parasitol. 2017:236:144-51.

16. Sobrinho LS, Rossi CN, Vides JP, Braga ET, Gomes AA, de Lima VM, et al. Coinfection of Leishmania chagasi with Toxoplasma gondii, Feline Immunodeficiency Virus (FIV) and Feline Leukemia Virus (FeLV) in cats from an endemic area of zoonotic visceral leishmaniasis. Vet Parasitol. 2012;187:302-6.

17. latta R, Furlanello T, Colella V, Tarallo VD, Latrofa MS, Brianti E, et al. A nationwide survey of Leishmania infantum infection in cats and associated risk factors in Italy. PLoS Negl Trop Dis. 2019;13:e0007594.

18. Persichetti MF, Solano-Gallego L, Serrano L, Altet L, Reale S, Masucci M, et al. Detection of vector-borne pathogens in cats and their ectoparasites in southern Italy. Parasit Vectors. 2016;9:247.

19. Pennisi MG, Hofmann-Lehmann R, Radford AD, Tasker S, Belák S, Addie DD, et al. Anaplasma, Ehrlichia and Rickettsia species infections in cats: European guidelines from the ABCD on prevention and management. J Feline Med Surg. 2017;19:542-8.

20. Morganti G, Veronesi F, Stefanetti V, Di Muccio T, Fiorentino E, Diaferia M, et al. Emerging feline vector-borne pathogens in Italy. Parasit Vectors. 2019;12:193.

21. Morelli S, Crisi PE, Di Cesare A, De Santis F, Barlaam A, Santoprete G, et al. Exposure of client-owned cats to zoonotic vector-borne pathogens: Clinic-pathological alterations and infection risk analysis. Comp Immunol Microbiol Infect Dis. 2019;66:101344

22. Tabar MD, Altet L, Francino O, Sánchez A, Ferrer L, Roura X. Vector-borne infections in cats: molecular study in Barcelona area (Spain). Vet Parasitol. 2008;151:332-6.

23. Diakou A, Di Cesare A, Accettura PM, Barros L, lorio R, Paoletti B, et al. Intestinal parasites and vector-borne pathogens in stray and freeroaming cats living in continental and insular Greece. PLoS Negl Trop Dis. 2017:11:e0005335. 
24. Maia C, Ramos C, Coimbra M, Bastos F, Martins A, Pinto P, et al. Bacterial and protozoal agents of feline vector-borne diseases in domestic and stray cats from southern Portugal. Parasit Vectors. 2014;7:115.

25. Bergmann M, Hartmann K. Vector-borne diseases in cats in Germany. Tierarztl Prax Ausg K Klientiere Heimtiere. 2017:45:329-35.

26. Ravagnan S, Carli E, Piseddu E, Da Rold G, Porcellato E, Zanardello C, et al. Prevalence and molecular characterization of canine and feline hemotropic mycoplasmas (hemoplasmas) in northern Italy. Parasit Vectors. 2017:10:132.

27. Tasker S, Hofmann-Lehmann R, Belák S, Frymus T, Addie DD, Pennisi MG, et al. Haemoplasmosis in cats: European guidelines from the ABCD on prevention and management. J Feline Med Surg. 2018;20:256-61.

28. Gubbels JM, de Vos AP, van der Weide M, Viseras J, Schouls LM, de Vries E, et al. Simultaneous detection of bovine Theileria and Babesia species by reverse line blot hybridization. J Clin Microbiol. 1999;37:1782-9.

29. Martin AR, Brown GK, Dunstan RH, Roberts TK. Anaplasma platys an improved PCR for the detection in dogs. Exp Parasitol. 2005;2005(109):176-80.

30. Otranto D, Brianti E, Dantas-Torres F, Weigl S, Latrofa MS, Gaglio G, et al. Morphological and molecular data on the dermal microfilariae of a species of Cercopithifilaria from a dog in Sicily. Vet Parasitol. 2011;182:221-9.

31. Willi B, Meli ML, Lüthy R, Honegger H, Wengi N, Hoelzle LE, et al. Development and application of a universal hemoplasma screening assay based on the SYBR Green PCR principle. J Clin Microb. 2009;47:4049-54.

32. Staggemeier R, Pilger DA, Spilki FR, Cantarelli W. Multiplex SYBR ${ }^{\circledR}$ green-real time PCR ( $(\mathrm{PCR}$ ) assay for the detection and differentiation of Bartonella henselae and Bartonella clarridgeiae in cats. Rev Inst Med Trop Sao Paulo. 2014,56:93-5.

33. Willi B, Filoni C, Catão-Dias JL, Cattori V, Meli ML, Vargas A, et al. Worldwide occurrence of feline hemoplasma infections in wild felid species. J Clin Microb. 2007:45:1159-66.

34. Kearse M, Moir R, Wilson A, Stones-Havas S, Cheung M, Sturrock S, et al. Geneious Basic: an integrated and extendable desktop software platform for the organization and analysis of sequence data. Bioinformatics. 2012:28:1647-9.

35. Beugnet F, Halos L. Parasitoses \& vector borne diseases of cats. 1st ed. Merial: Lyon; 2015

36. Chomel BB, Boulouis HJ, Breitschwerdt EB. Cat scratch disease and other zoonotic Bartonella infections. J Am Vet Med Assoc. 2004;224:1270-9.

37. Bergmann M, Englert T, Stuetzer B, Hawley JR, Lappin MR, Hartmann K. Prevalence of selected rickettsial infections in cats in Southern Germany. Comp Immunol Microbiol Infect Dis. 2015:42:33-6.

38. Chomel BB, Abbott RC, Kasten RW, Floyd-Hawkins KA, Kass PH, Glaser CA, et al. Bartonella henselae prevalence in domestic cats in California: risk factors and association between bacteremia and antibody titers. J Clin Microbiol. 1995:33:2445-50

39. Fabbi M, De Giuli L, Tranquillo M, Bragoni R, Casiraghi M, Genchi C. Prevalence of Bartonella henselae in Italian stray cats: evaluation of serology to assess the risk of transmission of Bartonella to humans. J Clin Microbiol. 2004:42:264-8.

40. Spada E, Proverbio D, Galluzzo P, Della Pepa A, De Bagnagatti Giorgi G, Perego $R$, et al. Prevalence of haemoplasma infections in stray cats in northern Italy. ISRN Microbiol. 2014;2014:298352.

41. Gentilini F, Novacco M, Turba ME, Willi B, Bacci ML, Hofmann-Lehmann R. Use of combined conventional and real-time PCR to determine the epidemiology of feline haemoplasma infections in northern Italy. J Fel Med Surg. 2009;11:277-85.

42. Willi B, Boretti FS, Baumgartner C, Tasker S, Wenger B, Cattori V, et al. Prevalence, risk factor analysis, and follow-up of infections caused by three feline haemoplasma species in cats in Switzerland. J Clin Microbiol. 2006:44:961e9.

43. Sarvani E, Tasker S, Kovaević Filipović M, Francuski Andrić J, Andrić N, Aquino $L$, et al. Prevalence and risk factor analysis for feline haemoplasmas in cats from Northern Serbia, with molecular subtyping of feline immunodeficiency virus. JFMS Open Rep. 2018;4:2055116918770037.
44. Martínez-Díaz VL, Silvestre-Ferreira AC, Vilhena H, Pastor J, Francino O, Altet L. Prevalence and co-infection of haemotropic mycoplasmas in Portuguese cats by real-time polymerase chain reaction. J Feline Med Surg. 2013;15:879-85

45. Roura X, Peters IR, Altet L, Tabar MD, Barker EN, Planellas M, Helps CR, et al. Prevalence of hemotropic mycoplasmas in healthy and unhealthy cats and dogs in Spain. J Vet Diagn Invest. 2010;22:270-4

46. Spada E, Proverbio D, Galluzzo P, Perego R, De Bagnagatti Giorgi G, Roggero N, et al. Frequency of piroplasms Babesia microti and Cytauxzoon felis in stray cats from northern Italy. Biomed Res Int. 2014;2014:943754.

47. Vilhena H, Martinez-Díaz VL, Cardoso L, Vieira L, Altet L, Francino O, et al. Feline vector-borne pathogens in the north and centre of Portugal. Parasit Vectors. 2013;6:99.

48. Giannelli A, Latrofa MS, Nachum-Biala Y, Hodžić A, Greco G, Attanasi A, et al. Three different Hepatozoon species in domestic cats from southern Italy. Ticks Tick-Borne Dis. 2017:8:721-4.

49. Díaz-Regañón D, Villaescusa A, Ayllón T, Rodríguez-Franco F, Baneth G, Calleja- Bueno L, et al. Molecular detection of Hepatozoon spp. and Cytauxzoon sp. in domestic and stray cats from Madrid. Spain. Parasit Vectors. 2017:10:112.

50. Ayllón T, Diniz PPVP, Breitschwerdt EB, Villaescusa A, Rodríguez-Franco F, Sainz A. Vector-borne diseases in client-owned and stray cats from Madrid, Spain. Vector Borne Zoonotic Dis. 2012;12:143-50.

51. Solano-Gallego L, Hegarty B, Espada Y, Llull J, Breitschwerdt E. Serological and molecular evidence of exposure to arthropod-borne organisms in cats from northeastern Spain. Vet Microbiol. 2006;118:274-7.

52. Alves AS, Milhano N, Santos-Silva M, Santos AS, Vilhena M, Sousa R. Evidence of Bartonella spp., Rickettsia spp. and Anaplasma phagocytophilum in domestic, shelter and stray cat blood and fleas, Portugal. Clin Microbiol Infect. 2009;15:1-3.

53. Hamel D, Bondarenko A, Silaghi C, Nolte I, Pfister K. Seroprevalence and bacteremia of Anaplasma phagocytophilum in cats from Bavaria and Lower Saxony (Germany). Berl Munch Tierarztl Wochenschr. 2012;125:163-7.

54. Elfving K, Malmsten J, Dalin AM, Nilsson K. Serological and molecular prevalence of Rickettsia helvetica and Anaplasma phagocytophilum in wild cervids and domestic mammals in the central parts of Sweden. Vector Borne Zoonotic Dis. 2015:15:529-34

55. Genchi M, Rinaldi L, Venco L, Cringoli G, Vismarra A, Kramer L. Dirofilaria immitis and D. repens in dog and cat: a questionnaire study in Italy. Vet Parasitol. 2019;267:26-31.

56. Angelakis E, Raoult D. Pathogenicity and treatment of Bartonella infections. Int J Antimicrob Agents. 2014;44:16-25.

57. dos Santos AP, dos Santos RP, Biondo AW, Dora JM, Goldani LZ, de Oliveira ST, et al. Hemoplasma infection in HIV-positive patient, Brazil. Emerg Infect Dis. 2008;14:1922-4.

\section{Publisher's Note}

Springer Nature remains neutral with regard to jurisdictional claims in published maps and institutional affiliations.
Ready to submit your research? Choose BMC and benefit from:

- fast, convenient online submission

- thorough peer review by experienced researchers in your field

- rapid publication on acceptance

- support for research data, including large and complex data types

- gold Open Access which fosters wider collaboration and increased citations

- maximum visibility for your research: over 100M website views per year

At BMC, research is always in progress.

Learn more biomedcentral.com/submissions 